\title{
Composição química de nozes e sementes comestíveis e sua relação com a nutrição e saúde ${ }^{1}$
}

\author{
Chemical composition of nuts and edible seeds \\ and their relation to nutrition and health
}

Jullyana Borges FREITAS²

Maria Margareth Veloso NAVES 3

\section{RE S U M O}

Esta revisão sistemática compara a composição química em nutrientes e outros compostos bioativos entre diferentes nozes e sementes comestíveis, relacionando-a com a nutrição e saúde. Foi realizada pesquisa bibliográfica nas bases Biological Abstracts, CAB Abstracts, Food Science and Technology Abstracts, Medline e Lilacs segundo os critérios de seleção: artigos de pesquisa original publicados nos últimos cinco anos em periódicos nacionais ou internacionais das áreas de Ciência de Alimentos, Medicina I e Medicina II, indexados no Institute for Scientific Information. Os artigos foram analisados conforme critérios de qualidade pré-estabelecidos. Nozes verdadeiras (amêndoas, avelãs, castanhas, castanhas-de-caju, castanhas-do-pará, macadâmias, nozes e pistaches) e sementes comestíveis (amendoim e amêndoa de baru) são boas fontes de lipídeos e proteínas. As frações lipídicas são compostas especialmente pelos ácidos graxos oléico (C18:1) e linoléico (C18:2), com destaque para a relação $\omega-6: \omega$-3 da macadâmia, noz, castanha e amêndoa de baru, perfil favorável à redução do risco de doenças cardiovasculares. As proteínas apresentam perfil de aminoácidos que atende grande parte das necessidades de escolares, contendo teores mais elevados de sulfurados que as leguminosas como feijões. Essas nozes e sementes comestíveis também são boas fontes de fitoesteróis, especialmente de $\beta$-sitoesterol; de minerais, sobretudo cálcio, ferro, zinco, selênio e potássio; de tocoferóis, com ênfase para o $\alpha$-tocoferol, e de fibras alimentares insolúveis. Esses alimentos contêm alta densidade de nutrientes e de substâncias bioativas que potencializam seus efeitos benéficos à saúde e, portanto, o estudo e o consumo deles devem ser estimulados.

Termos de indexação: Ácidos graxos. Aminoácidos. Minerais. Nozes. Nutrição. Semente comestíveis. Tocoferóis. Valor nutricional.

\footnotetext{
1 Apoio: Coordenação de Aperfeiçoamento de Pessoal de Nível Superior e projeto financiado pelo Conselho Nacional de Pesquisa (processo no 481669/2008-6)

2 Universidade Federal de Goiás, Escola de Agronomia e Engenharia de Alimentos. Goiânia, GO, Brasil.

${ }^{3}$ Universidade Federal de Goiás, Faculdade de Nutrição. R. 227, Quadra 68, Setor Leste Universitário, 74605-080, Goiânia, GO, Brasil. Correspondência para/Correspondence to: M.M.V. NAVES. E-mail: <mnaves@fanut.ufg.br>
} 


\section{A B S T R A C T}

This systematic review compares the chemical composition among different types of nuts and edible seeds with regard to nutrients and other bioactive compounds and relates this composition to nutrition and health. This literature review was based on Biological Abstracts, CAB Abstracts, Food Science and Technology Abstracts, Medline and Lilacs, in accordance with the following selection criteria: original research articles published in the last five years in Brazilian or international journals in the fields of Food Science, Medicine I and Medicine II, indexed in the Institute for Scientific Information. The articles were analyzed according to pre-established quality criteria. True nuts (almonds, hazelnuts, chestnuts, cashew nuts, Brazil nuts, macadamia nuts, walnuts and pistachios) and edible seeds (peanuts and baru almonds) are good sources of lipids and proteins. The lipid fractions are composed especially of oleic (C18:1) and linoleic (C18:2) fatty acids, with emphasis on the $\omega$-6 to $\omega$-3 relation in macadamia, walnut, chestnut and baru almond, whose profiles favor the reduction of cardiovascular disease risk. Their proteins present an amino acid profile that meets the requirements of school children and contain more sulfur-containing amino acids than legumes such as beans. These nuts and edible seeds are also good sources of phytoesterols, mainly $\beta$-sitosterol; minerals, particularly calcium, iron, zinc, selenium and potassium; tocopherols, especially $\alpha$-tocopherol; and insoluble fiber. These nutrient-dense foods contain bioactive substances that maximize their beneficial health effects and, for this reason, their study and consumption should be encouraged.

Indexing terms: Fatty acids. Amino acids. Minerals. Nuts. Tocopherols. Nutritive value.

\section{N T R O D U Ç Ã O}

As nozes verdadeiras são frutas secas, espessas e muitas vezes contêm espinhos que recobrem sua semente ${ }^{1}$. As mais conhecidas são: amêndoa, pecã, castanha-do-pará, castanha-de-caju, pistache, avelã, macadâmia, noz e castanha ${ }^{2}$. Além das nozes verdadeiras, existem muitas sementes comestíveis com características semelhantes a elas, mas com classificação botânica diferente. É o caso do amendoim, semente comestível de uma leguminosa herbácea, cujo pericarpo é espesso e seco'. Outro exemplo de semente comestível é a amêndoa de baru (Dipteryx alata Vog.), proveniente do fruto do barueiro, leguminosa arbórea lenhosa nativa do Cerrado. O baru é classificado como um fruto do tipo drupa, isto é, que possui uma polpa fibrosa com um centro endurecido contendo uma única semente comestível ${ }^{1,3}$.

As nozes verdadeiras e as sementes comestíveis, como o amendoim e a amêndoa de baru, contêm teores elevados de lipídeos (cerca de $40 \%$ a $60 \%$ ) e de proteínas $(8 \% \text { a } 20 \%)^{2,4,5}$, com exceção da castanha, que possui em torno de $6 \%$ de proteínas e apenas 2 a $3 \%$ de lipídeos ${ }^{6,7}$. Em relação à qualidade protéica, esses alimentos apresentam, de forma geral, um perfil de ami- noácidos essenciais que atende a maior parte das necessidades de escolares e de adultos, com exceção dos aminoácidos lisina e dos sulfurados (metionina e cisteína) $)^{2,4,8}$.

Além disso, as nozes verdadeiras e as sementes comestíveis são fontes de outros nutrientes e substâncias com propriedades de alegação de saúde, também denominados funcionais ou compostos biologicamente ativos. Dentre eles, destacam-se o perfil de ácidos graxos, contendo, sobretudo os ácidos oléico (C18:1) e linoléico (C18:2) e a relação $\omega-6: \omega-3$ da macadâmia ${ }^{2}$, noz ${ }^{2}$, castanha ${ }^{9}$ e da amêndoa de baru ${ }^{4,10}$; o conteúdo considerável de fitoesteróis, com 100 a 200 mg de $\beta$-sitosterol por 100 gramas de óleo ${ }^{11,12}$; os altos teores de vitamina $E$ e de selênio ${ }^{13-15}$ e, em alguns casos, de fibra alimentar, especialmente de fibras insolúveis ${ }^{2,16}$. O consumo elevado desses fitoquímicos está associado com a redução do risco de doenças cardiovasculares e de alguns tipos de câncer, como de próstata, esôfago, estômago, cólon e reto ${ }^{17,18}$.

Assim, o objetivo desta revisão sistemática é comparar a composição química em nutrientes e outros compostos bioativos entre diferentes nozes e sementes comestíveis, relacionando-a com a nutrição e saúde. 


\section{M É T O D O S}

A pesquisa bibliográfica foi realizada em cinco bases de dados, Biological Abstracts, $C A B$ Abstracts, Food Science and Technology Abstracts, Medline e Lilacs, no período de janeiro a novembro de 2008. A busca foi conduzida no módulo avançado, por meio da combinação de palavras-chave com os limites: artigos de periódicos, publicados após o ano de 2002. Dos resumos recuperados, foram selecionados os relativos a pesquisas originais, publicadas, em sua maioria, em periódicos indexados no Institute for Scientific Information (ISI). Entretanto, a maior parte do material bibliográfico relativo à amêndoa de baru não atendeu a alguns dos critérios de seleção, pela escassez de informações nutricionais sobre esse fruto do Cerrado na literatura. Nas bases Biological Abstracts, $C A B$ Abstracts e Food Science and Technology Abstracts foram usadas as palavras-chave nut, composition, amino acids e chestnuts. Na base de dados Medline foram utilizadas as palavras-chave glutamine, human, health, nut, cardiovascular, disease e selenium. Na base de dados Lilacs foram usadas as palavras-chave glutamina e rato. Além das bases de resumos, foi realizada busca direta em periódicos on line (Cancer Detection and Prevention, The Journal of Nutritional Biochemistry, e Nutrition, Metabolism \& Cardiovascular Diseases), por meio das palavras-chave sterols, cholesterol e cancer.

Os artigos científicos selecionados foram submetidos a avaliação e análise crítica, mediante o uso de uma planilha contendo dez critérios (avaliação geral: clareza, objetividade, lógica, consistência, coerência e coesão; título; resumo; introdução; material e tipo de estudo; métodos; resultados; discussão; conclusão e referências). Os artigos avaliados com nota 7,0 ou superior foram incorporados à presente revisão. Seu conteúdo foi sintetizado por tópicos em uma planilha-resumo, na qual eram registrados os dados de cada pesquisa revisada, como título, objetivo, tipo de estudo, metodologia, resultados principais, conclusão geral, informação de maior interesse e sua utilidade para a presente revisão. Foi dada prioridade de citação aos artigos que, além de atenderem aos pré-requisitos de seleção, obtiveram maiores notas na análise crítica e apresentaram conteúdo relevante. A amostra objeto desta revisão compreendeu 40 artigos científicos, sendo 38 artigos originais (23 observacionais [19 descritivos e 4 analíticos] e 15 experimentais), 1 meta-análise e 1 artigo de revisão. Além de artigos científicos, foram pesquisados materiais bibliográficos como livros e publicações técnico-científicas, que foram selecionados de acordo com a pertinência e relevância, dando-se preferência aos reconhecidos internacionalmente.

\section{COMPOSIÇÃO E M NUTRIENTES}

Composição centesimal: fonte de energia, lipídeos e proteínas.

As nozes verdadeiras, o amendoim e a amêndoa de baru apresentam quantidades consideráveis de lipídeos e proteínas, e, em decorrência disso, constituem boas fontes energéticas (Tabela 1). A relação entre proteínas e lipídeos das nozes e sementes com cerca de $60 \%$ de lipídeos é de $1: 4$, e naquelas que apresentam cerca de $40 \%$ de lipídeos, essa relação é reduzida de 1:2. Porém, a castanha é uma exceção, pois apresenta em torno de $6 \%$ de proteínas e apenas 2\% de lipídeos - relação de 3:1 (Tabela 1). Sendo assim, embora a castanha seja considerada uma noz verdadeira, segundo sua classificação botânica, o amendoim e a amêndoa de baru apresentam composição química mais similar às nozes, o que justifica o estudo em conjunto dessas sementes.

Em relação à composição protéica, há variação na literatura quanto ao fator de conversão de nitrogênio em proteína usado para quantificar a concentração de proteínas nas nozes e sementes comestíveis. Em alguns estudos, foram usados fatores de conversão específicos, sendo para a amêndoa, de 5,18; a avelã e demais nozes, de 5,30; e para o amendoim e a castanha-do-pará, de $5,46^{2,15}$. Em outros relatos, foi usado o fator 
272 | J.B. FREITAS \& M.M.V. NAVES

Tabela 1. Composição centesimal aproximada e valor energético de nozes verdadeiras e de sementes comestíveis.

\begin{tabular}{|c|c|c|c|c|c|c|c|c|}
\hline \multirow{2}{*}{$\begin{array}{l}\text { Noz/Semente comestível } \\
\text { (Fonte referência } n^{\circ} \text { ) }\end{array}$} & \multicolumn{8}{|c|}{ Componentes $\left(\mathrm{g} .100 \mathrm{~g}^{-1}\right)^{*}$} \\
\hline & Umidade & Lipídeos & Proteína & Nitrogênio & Carboidratos $^{\star \star}$ & $\begin{array}{c}\text { Fibra } \\
\text { alimentar }^{\star * *}\end{array}$ & Cinzas & $\begin{array}{c}\text { Valor } \\
\text { energético }^{* * * *}\end{array}$ \\
\hline Amêndoa $(2,19)$ & 9,51 & 45,93 & 21,41 & 3,75 & 20,67 & - & 2,48 & 581,69 \\
\hline Amendoim $(2,20)$ & 6,20 & 44,57 & 24,03 & 3,95 & 12,01 & 11,30 & 1,89 & 545,29 \\
\hline Avelã $(2,12,16,21,22)$ & 4,32 & 63,18 & 14,77 & 2,59 & 2,57 & 12,88 & 2,28 & 637,98 \\
\hline Amêndoa de baru $(4,5,10,23,24)$ & 4,83 & 41,04 & 26,22 & 4,20 & 10,95 & 13,90 & 3,06 & 518,04 \\
\hline Castanha $(6,7)$ & 53,82 & 2,52 & 6,60 & 1,31 & 34,75 & - & 2,31 & 188,08 \\
\hline Castanha-de-caju $(2,13)$ & 4,39 & 42,06 & 18,81 & 3,55 & 32,08 & - & 2,66 & 582,10 \\
\hline Castanha-do-pará $(2,13,15)$ & 3,10 & 64,94 & 14,11 & 2,62 & 6,27 & 8,02 & 3,56 & 665,98 \\
\hline Macadâmia (2) & 2,10 & 66,16 & 8,40 & 1,58 & 22,18 & - & 1,16 & 717,76 \\
\hline $\operatorname{Noz}(2,11)$ & 3,94 & 65,07 & 13,81 & 2,55 & 15,23 & - & 1,95 & 701,79 \\
\hline Pecã $(2,13)$ & 7,40 & 62,14 & 7,50 & 1,42 & 21,08 & - & 1,88 & 673,58 \\
\hline Pistache $(2,13,25,26)$ & 5,74 & 45,83 & 19,80 & 3,74 & 25,42 & - & 3,21 & 593,35 \\
\hline
\end{tabular}

*Valores se referem à média de dados da literatura (número de observações corresponde ao número de referências);

**Valores calculados por diferença. Nos casos em que não há dados de fibra alimentar, os valores correspondem aos carboidratos totais;

*** Fibra alimentar total (solúvel e insolúvel);

****Valor energético calculado considerando-se os fatores de conversão de Atwater de 4, 4 e 9 para proteína, carboidrato e lipídeo, respectivamente ${ }^{27}$.

6,25 para todos os tipos de nozes analisadas ${ }^{19,22}$. Segundo a Food and Agriculture Organization ${ }^{28}$, o fator de conversão para a maioria das nozes e sementes comestíveis é de 5,30. Assim, o uso do fator 6,25 pode superestimar a quantidade de proteína desses alimentos. Por causa dessa divergência, optou-se por apresentar na Tabela 1, além do teor protéico descrito na literatura, o respectivo percentual de nitrogênio, para permitir uma comparação mais precisa entre as fontes protéicas.

Outro fato que merece ser mencionado, é que existem variações significativas na composição centesimal de diferentes cultivares de nozes verdadeiras, como no caso de castanhas $^{7}$, avelãs ${ }^{12}$ e pistache ${ }^{25}$. Essa variação pode ser explicada pelas diferenças de clima, solo, práticas agrícolas e características genéticas das sementes analisadas. Sendo assim, dados sobre o teor de nutrientes desses alimentos precisam ser obtidos levando-se em consideração variáveis como procedência geográfica, condições ambientais e caracterização varietal das nozes e sementes comestíveis ${ }^{29}$.

Perfil de aminoácidos e qualidade protéica: atende grande parte das necessidades de escolares e adultos.
Além da quantidade de proteínas, a qualidade protéica das nozes e sementes comestíveis deve ser investigada por se tratar de aspecto relevante para a nutrição humana, incluindo a avaliação da biodisponibilidade de seus aminoácidos essenciais ${ }^{8}$.

De forma geral, proteínas de nozes e de sementes comestíveis atendem a grande parte das necessidades de aminoácidos essenciais de escolares e de indivíduos adultos, com exceção dos aminoácidos lisina, metionina e cisteína (Tabela 2), que estão deficientes em alguns desses alimentos, em comparação aos padrões mais recentes da World Health Organization (WHO) ${ }^{8}$ e do Instituto de Medicina dos EUA ${ }^{30-31}$. No caso da proteína da amêndoa de baru, Togashi \& Sgarbieri ${ }^{4}$ constataram deficiência considerável em aminoácidos sulfurados, perfil que corresponde a apenas 35\% das necessidades, segundo o padrão $\mathrm{WHO}^{8}$, e que se assemelha ao de proteínas de leguminosas, como o feijão ${ }^{28}$. Todavia, estudo recente sobre o teor de aminoácidos de amêndoas de baru, oriundas de diferentes plantas da região Sudeste do Estado de Goiás, revelou um conteúdo de aminoácidos que corresponde em média a 92\% das necessidades de sulfurados ${ }^{24}$, e que é, portanto, 
similar ao de outras nozes e sementes comestíveis e superior ao de feijões. Essas diferenças podem ser explicadas por variações genéticas e pela procedência das sementes analisadas, o que denota a biodiversidade dos frutos do Cerrado.

Além dos aminoácidos essenciais, destaca-se o conteúdo de glutamina desses alimentos (Tabela 2), por ser considerado um aminoácido condicionalmente essencial para indivíduos catabólicos, como desnutridos, queimados, em pós-operatório, entre outros. A importância da glutamina nessas condições especiais deve-se às suas funções no organismo, dentre quais: precursora da síntese de nucleotídeos, substrato para a gliconeogênese hepática, além de ser fonte energética importante para as células do epitélio gastrintestinal, linfócitos, fibroblastos e reticulócitos ${ }^{32,33}$. Nesse sentido, estudos têm confirmado que a suplementação com glutamina, em ratos imunodeprimidos ${ }^{32}$ ou submetidos à ressecção intestinal ${ }^{33}$, melhora a resposta imunológica e estimula as funções da mucosa intestinal, respectivamente. Em humanos, foi constatada a eficácia do uso de glutamina em aumentar a sobrevida de pacientes críticos internados em unidades de terapia intensiva durante seis meses, recebendo nutrição parenteral enriquecida com 2,5\% de glutamina ${ }^{34}$.

Assim, o consumo dessas nozes e sementes comestíveis contribui para suprir as necessidades de aminoácidos essenciais, e pode auxiliar na recuperação da saúde de indivíduos com grandes complicações nutricionais.

Perfil de ácidos graxos: favorável à saúde.

Quanto à composição em ácidos graxos, o óleo de nozes e sementes comestíveis é composto principalmente pelos ácidos graxos oléico (C18:1) e linoléico (C18:2) (Tabela 3). Essa composição em ácidos graxos mono e poliinsaturado é importante para a saúde, uma vez que esses ácidos contribuem para a redução das frações de Lipoproteína de Baixa Densidade (LDL) e de Muito Baixa Densidade (VLDL), responsáveis pelo aumento do colesterol sérico ${ }^{17}$. O efeito benéfico do consumo de nozes e sementes comestíveis sobre o perfil sérico lipídico tem sido confirmado em diversos

Tabela 2. Composição em aminoácidos de nozes verdadeiras e de sementes comestíveis em comparação ao padrão WHO/ FAO/UNU de aminoácidos essenciais.

\begin{tabular}{|c|c|c|c|c|c|c|c|c|c|c|c|c|c|c|c|c|c|}
\hline \multirow{3}{*}{\multicolumn{2}{|c|}{$\begin{array}{l}\text { Nozes e } \\
\text { sementes comestíveis }\end{array}$}} & \multicolumn{16}{|c|}{ Aminoácido (mg. $\mathrm{g}^{-1}$ de proteína) } \\
\hline & & \multicolumn{9}{|c|}{ Essencial } & \multicolumn{7}{|c|}{ Não-essencial } \\
\hline & & His & lle & Leu & Lys & $\begin{array}{c}\text { Met } \\
+ \\
\text { Cys }\end{array}$ & $\begin{array}{c}\text { Phe } \\
+ \\
\text { Tyr }\end{array}$ & Thr & Trp & Val & Asp & Glu & Ala & Arg & Gly & Pro & Ser \\
\hline \multicolumn{2}{|l|}{ Amêndoa } & 29,7 & 37,9 & 71,9 & 30,6 & 11,1 & 76,7 & 26,0 & 7,0 & 44,1 & - & - & 48,5 & 100,9 & 68,8 & 50,9 & 36,7 \\
\hline \multicolumn{2}{|l|}{ Amendoim } & 25,4 & 34,5 & 70,3 & 38,8 & 16,4 & 87,8 & 22,1 & 7,3 & 39,5 & - & - & 45,8 & 110,4 & 64,3 & 58,1 & 48,1 \\
\hline \multicolumn{2}{|l|}{ Avelã } & 26,5 & 36,9 & 74,0 & 29,3 & 24,2 & 73,6 & 29,5 & 9,8 & 46,6 & - & - & 51,2 & 125,1 & 47,3 & 48,1 & 46,9 \\
\hline \multicolumn{2}{|c|}{ Amêndoa de baru } & 23,4 & 37,5 & 77,8 & 48,4 & 22,0 & 77,2 & 44,9 & 20,2 & 51,8 & 101,6 & 216,8 & 46,1 & 85,6 & 47,2 & 55,3 & 44,1 \\
\hline \multicolumn{2}{|c|}{ Castanha } & 57,0 & 58,6 & 93,1 & 79,3 & 9,1 & 74,2 & 41,4 & - & 70,7 & 175,9 & 131,0 & 103,4 & 93,1 & 67,2 & 43,1 & 51,7 \\
\hline \multicolumn{2}{|c|}{ Castanha-de-caju } & 26,8 & 41,5 & 80,0 & 45,9 & 28,1 & 72,6 & 32,2 & 13,1 & 56,5 & - & - & 44,4 & 98,4 & 45,5 & 53,7 & 52,1 \\
\hline \multicolumn{2}{|c|}{ Castanha-do-pará } & 30,2 & 31,5 & 82,4 & 37,4 & 95,9 & 71,8 & 26,4 & 10,1 & 49,2 & 101,1 & 250,1 & 43,0 & 151,0 & 52,4 & 49,8 & 46,2 \\
\hline \multicolumn{2}{|c|}{ Macadâmia } & 24,5 & 32,6 & 65,5 & 41,0 & 29,9 & 76,5 & 28,1 & 5,9 & 43,1 & - & - & 45,1 & 125,3 & 48,7 & 67,7 & 43,0 \\
\hline \multicolumn{2}{|l|}{$\mathrm{Noz}$} & 24,3 & 40,0 & 77,6 & 27,1 & 21,9 & 80,4 & 30,0 & 5,5 & 46,1 & - & - & 46,9 & 138,0 & 48,9 & 55,0 & 53,3 \\
\hline \multicolumn{2}{|l|}{ Pecã } & 28,0 & 40,8 & 75,1 & 31,7 & 29,7 & 81,0 & 29,0 & 4,7 & 47,2 & - & - & 50,6 & 124,5 & 47,3 & 55,0 & 52,1 \\
\hline \multicolumn{2}{|l|}{ Pistache } & 23,8 & 41,0 & 75,6 & 46,4 & 24,1 & 73,2 & 29,7 & 7,8 & 56,9 & - & - & 47,8 & 91,5 & 49,3 & 55,3 & 62,5 \\
\hline Padrão & Escolar & 16 & 31 & 61 & 48 & 24 & 41 & 25 & 6,6 & 40 & - & - & - & - & - & - & - \\
\hline FAOMHO & Adulto & 15 & 30 & 59 & 45 & 22 & 38 & 23 & 6 & 39 & - & - & - & - & - & - & - \\
\hline
\end{tabular}

*Para crianças em idade escolar e adultos ${ }^{8}$.

Valores sombreados correspondem aos aminoácidos que, em geral, em nozes e sementes comestíveis, estão em quantidades limitantes em relação às necessidades de crianças em idade escolar.

Fonte: Venkatachalam \& Sathe², exceto para amêndoa de baru'24, castanha ${ }^{30}$ e castanha-do-pará2,15 (valores médios). 
trabalhos. Estudos constataram um efeito positivo no perfil sérico lipídico de pacientes com hiperlipidemia moderada que consumiram $40 \mathrm{~g}$ a $75 \mathrm{~g} / \mathrm{dia}$ de amêndoas e nozes durante um mês ${ }^{17,35}$. Além disso, em indivíduos adultos normolipidêmicos, o consumo de cerca de $100 \mathrm{~g}$ de amendoim por sete meses alterou positivamente o perfil sérico lipídico dos voluntários ${ }^{36}$. Por outro lado, em pesquisa mais recente com suplementação de $45 \mathrm{~g}$ de castanha-do-pará durante quinze dias, não foi observado qualquer efeito no perfil lipídico de adultos saudáveis $^{37}$, o que pode estar relacionado com o perfil de ácidos graxos da castanha-do-pará, que apresenta teor mais elevado de ácidos graxos saturados em relação às demais nozes (Tabela 3 ).

Além disso, a Organizacion Mundial de la Salude ${ }^{38}$ recomenda que a relação $\omega-6: \omega-3$ da dieta seja de 5:1 a 10:1, visto que a alta ingestão de ácido graxo linoléico, associada ao baixo consumo de ácido graxo linolênico, contribui para o desenvolvimento de doenças cardiovasculares. Assim, dentre as nozes e sementes comestíveis estudadas nesta revisão, a macadâmia possui a melhor proporção de ácidos graxos $\omega-6 / \omega-3$, seguida pela noz, castanha e amêndoa de baru (Tabela 3). Isto reforça a importância da especiação dos nutrientes e demais compostos bioativos presentes em nozes e sementes comestíveis, e de estudos dos seus efeitos sobre a nutrição e saúde de humanos.

Conteúdo em minerais: recomendável no combate às carências nutricionais e hipertensão arterial.

As nozes e sementes comestíveis também apresentam teor considerável de diversos minerais (Tabela 4). Destaca-se, dentre os minerais, a composição em ferro, cálcio, zinco e selênio, pela importância dos dois primeiros na prevenção de carências nutricionais de relevância em saúde coletiva, e pelas funções enzimáticas e reguladoras do zinco e do selênio, como parte do sistema de defesa antioxidante do organismo ${ }^{39-42}$.

Estudos constataram teores elevados de selênio em amêndoas ${ }^{14}$, avelãs ${ }^{14,16}$, pistache ${ }^{14}, \mathrm{e}$,

Tabela 3. Composição em ácidos graxos de nozes verdadeiras e sementes comestíveis.

\begin{tabular}{|c|c|c|c|c|c|c|c|c|c|c|c|}
\hline \multirow[b]{2}{*}{$\begin{array}{l}\text { Ácidos } \\
\text { graxos (g.100 } \mathrm{g}^{-1} \\
\text { de lipídeos) }\end{array}$} & \multicolumn{11}{|c|}{ Nozes e sementes comestíveis ${ }^{*}$} \\
\hline & $\begin{array}{c}\text { Amêndoa } \\
(2,19)^{*}\end{array}$ & $\begin{array}{c}\text { Amêndoim } \\
\text { (20) }\end{array}$ & $\begin{array}{c}\text { Avelã } \\
(2,12,16, \\
21,22)\end{array}$ & $\begin{array}{c}\text { Amêndoa } \\
\text { de baru } \\
(4-10)\end{array}$ & $\begin{array}{c}\text { Castanha } \\
\text { (9) }\end{array}$ & $\begin{array}{c}\text { Castanha- } \\
\text {-de-caju } \\
(2,13)\end{array}$ & $\begin{array}{c}\text { Castanha- } \\
\text {-do-pará } \\
(2,13)\end{array}$ & $\begin{array}{l}\text { Macadâmia } \\
\text { (2) }\end{array}$ & $\begin{array}{c}\mathrm{Noz} \\
(2,11)\end{array}$ & $\begin{array}{l}\text { Pecã } \\
(2,13)\end{array}$ & $\begin{array}{c}\text { Pistache } \\
(2,25)\end{array}$ \\
\hline Sat $^{\star *}$ & 9,19 & 14,81 & 8,25 & 18,77 & 15,81 & 20,66 & 25,47 & 16,09 & 9,81 & 7,33 & 14,60 \\
\hline Palmítico C16:0 & 7,43 & 7,20 & 5,57 & 7,39 & 14,46 & 10,32 & 14,31 & 8,88 & 7,15 & 5,09 & 12,61 \\
\hline Esteárico C18:0 & 1,70 & 1,84 & 2,50 & 4,62 & 0,89 & 9,02 & 10,64 & 4,26 & 2,55 & 2,02 & 1,42 \\
\hline Araquídico C20:0 & 0,06 & 1,19 & 0,14 & 1,10 & 0,26 & 0,80 & 0,40 & 2,95 & 0,07 & 0,06 & 0,35 \\
\hline Behênico C22:0 & - & 2,85 & 0,03 & 2,64 & 0,10 & 0,39 & 0,12 & - & 0,04 & 0,16 & 0,22 \\
\hline Lignocérico C24:0 & - & 1,73 & 0,01 & 3,02 & 0,10 & 0,13 & - & - & - & - & 0,00 \\
\hline Mono ${ }^{*}$ & 65,89 & 43,93 & 80,62 & 51,07 & 29,19 & 59,33 & 29,03 & 58,51 & 16,30 & 54,26 & 56,28 \\
\hline Oléico C18:1 & 65,89 & 42,48 & 80,52 & 48,37 & 28,60 & 59,20 & 28,92 & 58,51 & 16,14 & 53,65 & 55,98 \\
\hline Gadoléico C20:1 & 0,00 & 1,45 & 0,10 & 2,70 & 0,59 & 0,13 & 0,11 & 0,00 & 0,16 & 0,61 & 0,30 \\
\hline Poli $^{* *}$ & 23,95 & 37,81 & 10,57 & 32,35 & 52,20 & 19,12 & 44,31 & 4,39 & 72,79 & 37,95 & 27,11 \\
\hline Linoléico C18:2 & 23,85 & 37,52 & 10,43 & 30,13 & 45,65 & 18,84 & 44,12 & 1,81 & 60,23 & 37,00 & 26,55 \\
\hline Linolênico C18:3 & 0,10 & 0,29 & 0,14 & 2,22 & 6,55 & 0,28 & 0,19 & 2,58 & 12,56 & 0,95 & 0,56 \\
\hline$\omega-6 / \omega-3^{* * *}$ & 238,50 & 129,38 & 74,50 & 13,57 & 6,97 & 67,29 & 232,21 & 0,70 & 4,80 & 38,95 & 47,41 \\
\hline
\end{tabular}

*Números entre parênteses correspondem à fonte bibliográfica ( $n^{\circ}$ da referência) dos dados. No caso de duas ou mais fontes, os valores constituem média dos dados encontrados na literatura.

Valores sombreados: destaque para os teores elevados de C 18:1 e C 18:2 nesses alimentos.

**at: total de ácidos graxos saturados; Mono: total de ácidos graxos monoinsaturados; Poli: total de ácidos graxos poliinsaturados.

${ }^{* * *}$ Relação dos ácidos graxos linoléico ( $\omega$-6) e linolênico ( $\omega$-3). 
sobretudo, na castanha-do-pará (Tabela 4) ${ }^{15}$. Em adultos saudáveis, foi observado que a concentração do selênio plasmático aumentou significativamente após o consumo de $45 \mathrm{~g}$ de castanhas-do-pará por dia ${ }^{37}$, durante duas semanas. De forma similar, o consumo de 100 $\mu \mathrm{g}$ de selênio/dia (duas unidades de castanhas-do-pará), durante três meses, foi eficiente tanto quanto a selenometionina na elevação plasmática do selênio e da glutationa peroxidase, em indivíduos saudáveis. Nesse mesmo estudo, constatou-se, ainda, que a atividade da glutationa peroxidase foi maior no grupo que ingeriu castanha-do-pará, em relação aos demais grupos, o que reforça o potencial antioxidante dessa noz ${ }^{43}$.

Além desses minerais, é importante ressaltar o alto teor de potássio e a reduzida concentração de sódio nas nozes verdadeiras e sementes comestíveis (Tabela 4), cuja composição pode favorecer o controle hidroeletrolítico e da pressão arterial, contribuindo assim para a manutenção da saúde ${ }^{44}$.

\section{CONTEÚ DO EM SU BSTÂNCIAS COM PROPRIEDADES DE A LE G A ÇÃO DE S A Ú DE}

Composição em esteróis: saúde cardiovascular e possível proteção contra câncer.
As nozes e sementes comestíveis contêm teores consideráveis de fitoesteróis, sendo o $\beta$-sitoesterol o componente principal, presente na concentração aproximada de $120 \mathrm{mg}^{1} 100 \mathrm{~g}^{-1}$, em óleo de nozes, avelãs e pistache ${ }^{11-13,26}$ e, em média, $380 \mathrm{mg}^{1}$ 100g $^{-1}$, em óleo de amendoim ${ }^{45}$. Entretanto, pesquisas sobre a composição de fitoesteróis desses alimentos são escassas na literatura. A investigação do tema é relevante, pois os fitoesteróis apresentam estrutura química similar ao colesterol, e por isso, podem inibir sua absorção intestinal e reduzir a fração LDL e o colesterol total plasmáticos ${ }^{46,47}$. Esse efeito dos fitoesteróis sobre o perfil sérico lipídico foi evidenciado em meta-análise de 41 estudos que investigaram a eficácia do uso de fitoesteróis na redução do LDL-colesterol sanguíneo. A partir dessa meta-análise, foi possível concluir que a ingestão de $2 \mathrm{~g}$ de fitoesteróis/dia reduz o LDL em 10\%, e quando esse consumo é associado a uma dieta baixa em gordura saturada e colesterol, essa redução pode atingir $20 \%{ }^{48}$.

Além dessa atividade, estudos epidemiológicos e experimentais sugerem que os fitoesteróis podem reduzir o risco de cânceres de cólon, mama e próstata. Os possíveis mecanismos de proteção dos fitoesteróis apontados na literatura incluem sua ação benéfica sobre a estrutura, fluidez e funções enzimáticas das membranas celulares, além do estímulo à apoptose e à função imune celular,

Tabela 4. Composição em minerais de nozes verdadeiras e sementes comestíveis.

\begin{tabular}{|c|c|c|c|c|c|c|c|}
\hline \multirow{2}{*}{$\begin{array}{l}\text { Minerais } \\
\left(\mathrm{mg}_{\left.100 \mathrm{~g}^{1}\right)}\right.\end{array}$} & \multicolumn{7}{|c|}{ Nozes e sementes comestíveis* } \\
\hline & $\begin{array}{c}\text { Amêndoa } \\
(14)^{*}\end{array}$ & $\begin{array}{l}\text { Amêndoim } \\
\text { (20) }\end{array}$ & $\begin{array}{c}\text { Avelã } \\
(14,16,22)\end{array}$ & $\begin{array}{c}\text { Amêndoa de } \\
\text { baru }(10,23,24)\end{array}$ & $\begin{array}{c}\text { Castanha } \\
\text { (30) }\end{array}$ & $\begin{array}{c}\text { Castanha-do-pará } \\
\text { (15) }\end{array}$ & $\begin{array}{l}\text { Pistache } \\
(14,25)\end{array}$ \\
\hline $\mathrm{Ca}$ & - & 83,22 & 189,70 & 120,40 & 44,75 & - & - \\
\hline $\mathrm{Fe}$ & - & 2,48 & 4,59 & 4,85 & 7,35 & - & - \\
\hline Zn & - & 3,50 & 2,42 & 3,66 & 1,99 & - & - \\
\hline $\mathrm{Mg}$ & - & 199,25 & 174,75 & - & 74,59 & - & 141,60 \\
\hline K & - & 584,20 & 812,00 & 819,00 & 754,50 & - & 724,63 \\
\hline $\mathrm{Na}$ & - & 25,88 & 2,87 & 3,30 & 1,72 & - & 11,71 \\
\hline $\mathrm{Cu}$ & - & 1,18 & 1,95 & 1,26 & 1,88 & - & 1,34 \\
\hline P & - & 390,90 & 321,35 & 337,50 & 123,62 & - & - \\
\hline $\mathrm{Mn}$ & - & - & 4,44 & 7,02 & 5,34 & - & 141,06 \\
\hline $\operatorname{Se}\left(\mu \mathrm{g} .100 \mathrm{~g}^{-1}\right)$ & 52,00 & - & 90,00 & - & - & 204,00 & 85,00 \\
\hline
\end{tabular}

*Números entre parênteses correspondem à fonte bibliográfica ( $n^{\circ}$ da referência) dos dados. No caso de duas ou mais fontes, os valores constituem média dos dados encontrados na literatura. 
e inibição de metástase ${ }^{49,50}$. Awad et al. ${ }^{49}$ observaram maior efeito protetor do $\beta$-sitoesterol contra câncer de mama em comparação ao campesterol, o que evidencia a importância da especiação dos diferentes tipos de fitoesteróis existentes nos alimentos. Ressalta-se que a interação entre fitoesteróis e outros fitoquímicos dietéticos, como tocoferóis e demais antioxidantes naturais, tem sido associada com a redução do risco de desenvolvimento de câncer $^{18}$. Assim, é recomendável o consumo de alimentos que contêm quantidades significativas desses compostos, como é o caso das nozes e sementes comestíveis.

Conteúdo em tocoferóis: ação antioxidante.

As nozes e sementes comestíveis também são boas fontes de vitamina $\mathrm{E}$ para a alimentação humana (Tabela 5), com destaque para o $\alpha$-tocoferol. A vitamina E é parte do sistema de defesa antioxidante do organismo, desempenhando diversas ações, como inibição da oxidação lipídica e proteção contra o estresse oxidativo. Pode agir, ainda, como substância protetora contra alguns tipos de cânceres, como o de próstata e de esôfago $^{18,51-52}$.

Associada ao conteúdo em tocoferóis, a composição em selênio ${ }^{14,53}$ e zinco ${ }^{54}$ das nozes verdadeiras e sementes comestíveis (Tabela 4) reforça o potencial antioxidante desses alimentos.

Conteúdo em fibras alimentares: saúde do intestino.

A avelã, o amendoim, a amêndoa de baru e a castanha-do-pará são boas fontes de fibras alimentares (Tabela 1), presentes nas concentrações média de 14\% na amêndoa de baru ${ }^{4,23,24}$, $10 \%$ na avelă ${ }^{16}$ e de $5 \%$ na castanha-do-pará 15 , com predominância de fibras insolúveis. Esses teores consideráveis de fibras insolúveis, cujo consumo está associado ao aumento do bolo fecal e à prevenção de problemas entéricos, valorizam ainda mais esses alimentos na promoção da saúde ${ }^{55}$.

Ingestão de nozes e sementes comestíveis: prevenção de câncer.

De acordo com resultados preliminares do estudo de coorte denominado European Prospective Investigation into Cancer and Nutrition (EPIC), a ingestão diária de cerca de $15 \mathrm{~g}$ de nozes e sementes está associada ao menor risco de câncer de cólon em mulheres ${ }^{56}$. Os autores do estudo citado sugerem a realização de outras pesquisas para definir os níveis de ingestão que poderiam assegurar esse efeito protetor em diversos tipos de câncer. O possível efeito protetor das nozes contra alguns cânceres (próstata, esôfago, estômago, cólon e reto) está associado aos teores significativos de diversos compostos bioativos existentes nesses alimentos, descritos na presente revisão ${ }^{18}$. Além disso, existem evidências de que o consumo de substâncias antioxidantes, presentes em nozes e sementes comestíveis, reduz o risco de câncer de próstata ${ }^{18}$. Deve-se investigar, portanto, a composição desses alimentos em nutrientes e em outras substâncias biologicamente ativas, considerando as diversas variedades e os diferentes locais de procedência, assim como seus efeitos sobre a saúde.

Tabela 5. Composição em tocoferóis de nozes verdadeiras e sementes comestíveis.

\begin{tabular}{lcccccrc}
\hline $\begin{array}{l}\text { Tocoferóis } \\
\text { (mg.100g }\end{array}$ & \multicolumn{7}{c}{ Nozes e sementes comestíveis $^{*}$} \\
\cline { 2 - 8 } de óleo) & $\begin{array}{c}\text { Amêndoa } \\
(45)^{*}\end{array}$ & $\begin{array}{c}\text { Avelã } \\
(16,22)\end{array}$ & $\begin{array}{c}\text { Castanha-de-caju } \\
(13)\end{array}$ & $\begin{array}{c}\text { Castanha-do-pará } \\
(13)\end{array}$ & $\begin{array}{c}\text { Noz } \\
(51)\end{array}$ & $\begin{array}{c}\text { Pecã } \\
(13)\end{array}$ & $\begin{array}{c}\text { Pistache } \\
(13,26)\end{array}$ \\
\hline$\alpha$-tocoferol & 15,80 & 31,47 & 3,60 & 82,90 & 1,21 & 12,80 & 14,55 \\
$\beta$-tocoferol & 0,83 & 1,15 & - & - & 0,10 & - & 0,32 \\
$\gamma$-tocoferol & 8,32 & 2,63 & 57,20 & 116,20 & 22,65 & 168,50 & 144,48 \\
$\delta$-tocoferol & 4,77 & 0,98 & - & - & 1,23 & - & 0,83 \\
\hline
\end{tabular}

*Números entre parênteses correspondem à fonte bibliográfica ( $n^{\circ}$ da referência) dos dados. No caso de duas ou mais fontes, os valores constituem média dos dados encontrados na literatura. 


\section{CONSIDERAÇÕES FINAIS}

- As nozes verdadeiras e as sementes comestíveis regionais têm composição química inter e intraespecífica variável, inclusive em macronutrientes, tais como lipídeos e proteínas, o que confirma a biodiversidade desses alimentos.

- As nozes e sementes apresentam melhor perfil de aminoácidos em comparação a leguminosas como o feijão, e perfil de ácidos graxos benéfico ao organismo, destacando-se a macadâmia, noz, castanha e amêndoa de baru.

- Esses alimentos possuem outros compostos químicos como fitoesteróis, selênio e tocoferóis que potencializam sua ação antioxidante, inibitória de estresse oxidativo.

- Considerando as propriedades nutricionais e as alegações de saúde, estudos sobre o tema e o consumo de nozes e sementes comestíveis devem ser estimulados.

\section{COLABORADORES}

J.B. FREITAS contribuiu substancialmente na revisão da literatura, na análise e na síntese dos dados e na redação do trabalho. M.M.V. NAVES orientou a concepção do trabalho (ideia e planejamento) e contribuiu na redação e na revisão crítica do manuscrito.

\section{REFERÊ N CIAS}

1. Judd WS, Campbell CS, Kellogg EA, Stevens PF, Donoghue MJ. Taxonomic evidence: structural and biochemical characters. In: Judd WS, Campbell CS, Kellogg EA, Stevens PF, Donoghue MJ. Plant systematics: a phylogentetic approach. $2^{\text {nd }}$ ed. Massachusetts: Sunderland; 2002. p.55-104.

2. Venkatachalam M, Sathe SK. Chemical composition of selected edible nut seeds. J Agric Food Chem. 2006; 54(13):4705-14. doi: 10.1021/ jf0606959.

3. Lorenzi H. Árvores brasileiras: manual de identificação e cultivo de plantas arbóreas nativas do Brasil. 4a ed. São Paulo: Instituto Plantarum; 2002.

4. Togashi M, Sgarbieri VC. Caracterização química parcial do fruto do baru (Dipteryx alata, Vog.). Ciênc Tecnol Aliment. 1994; 14(1):85-95.
5. Togashi M, Sgarbieri VC. Avaliação nutricional da proteína e do óleo de sementes de baru (Dipteryx alata, Vog.). Ciênc Tecnol Aliment. 1995; 15(1): 66-9.

6. Míguelez JM, Bernárdez MM, Queijeiro JMG. Composition of varieties of chestnuts from Galicia (Spain). Food Chem. 2003; 84(3):401-4. doi: 10.10 16/S0308-8146(03)00249-8.

7. Pereira-Lorenzo S, Ramos-Cabrer AM, DíazHernández MB, Ciordia-Ara M, Ríos-Mesa D. Chemical composition of chestnut cultivars from Spain. Scientia Horticulturae. 2006; 107(3):306-14. doi: 10.1016/j.scienta.2005.08.008.

8. World Health Organization. Report of a Joint WHO/ FAO/UNU Expert Consultation. Protein and amino acid requirements in human nutrition. Geneva: WHO; 2007. WHO Technical Report Series, n. 935.

9. Borges OP, Carvalho, JS, Correia PR, Silva AP. Lipid and fatty acid profiles of Castanea sativa Mill. Chestnuts of 17 native Portuguese cultivars. J Food Compos Anal. 2007; 20(2):80-9. doi: 10.1016/ j.jfca.2006.07.008.

10. Vallilo MI, Tavares M, Aued S. Composição química da polpa e da semente do fruto do cumbaru (Dipteryx alata Vog)- caracterização do óleo da semente. Rev Inst Florest. 1990; 2(2):115-25.

11. Amaral JS, Casal S, Pereira JA, Seabra RM, Oliveira BPP. Determination of sterol and fatty acid compositions, oxidative stability, and nutritional value of six walnut (Juglans regia L.) cultivars grown in Portugal. J Agric Food Chem. 2003; 51(26): 7698-702. doi: 10.1021/jf030451d.

12. Amaral JS, Casal S, Citová I, Santos, A, Seabra RM, Oliveira BPP. Characterization of several hazelnut (Corylus avellana L.) cultivars based in chemical, fatty acid and sterol composition. Eur Food Res Technol. 2006; 222(3-4):274-80. doi: 10.1007/s00 217-005-0068-0.

13. Ryan E, Galvin K, O'Connor TP, Maguire, AR, O'Brien NM. Fatty acid profile, tocopherol, squalene and phytosterol content of brazil, pecan, pine, pistachio and cashew nuts. Int J Food Sci Nutr. 2006; 54 (3-4):219-28. doi: 10.1080/096374806007680 77.

14. Dugo G, La Pera L, Lo Turco V, Mavrogeni E, Alfa $M$. Determination of selenium in nuts by cathodic tripping potentiometry (CSP). J Agric Food Chem. 2003; 51(13):3722-5. doi: 10.1021/jf021256m.

15. Souza ML, Menezes HC. Processamentos de amêndoa e torta de castanha-do-brasil e farinha de mandioca: parâmetros de qualidade. Ciênc Tecnol Aliment. 2004; 24(1):120-8. doi: 10.1590/ S0101-20612004000100022.

16. Alasalvar C, Shahidi F, Liyanapathirana CM, Ohshima T. Turkish tombul hazelnut (Corylus 
avellana L.). 1. Compositional characteristics. J Agric Food Chem. 2003; 51(13):3790-6. doi: 10.1021/jf0 212385.

17. Jenkins DJ, Kendall CW, Marchie A, Parker TL, Connelly PW, Qian W, et al. Dose response of almonds on coronary heart disease risk factors: blood lipids, oxidized low-density lipoproteins, lipoprotein(a), homocysteine, and pulmonary nitric oxide. A randomized, controlled, crossover trial. Circulation. 2002; 106(11):1327-32. doi: 10.1161/ 01.CIR.0000028421.91733.20.

18. World Cancer Research Fund. Food, nutrition, physical activity, and prevention of cancer: a global perspective. Washington (DC): AICR; 2007.

19. Askin MA, Balta MF, Tekintas FE, Kazankaya A, Balta F. Fatty acid composition affected by kernel weight in almond [Prunus dulcis (Mill.) D.A. Webb.] genetic resources. J Food Compos Anal. 2007; 20(1):7-12. doi:10.1016/j.jfca.2006.06.005.

20. Jonnala RS, Dunford NT, Chenault K. Nutritional composition of genetically modified peanut varieties. J Food Sci. 2005; 70(4):254-6. doi: 10.1111/j.1365-2621.2005.tb07198.x.

21. Balta MF, Yarilgaç T, A şkin MA, Kuçuk M, Balta F, Özrenk K. Determination of fatty acid compositions, oil contents and some quality traits of hazelnut genetic resources grown in eastern Anatolia of Turkey. J Food Compos Anal. 2006; 19(6-7):681-6. doi:10.1016/j.jfca.2005.10.007.

22. Köksal Al, Artik N, A, Şimşek A, Güne ${ }^{\$}$ N. Nutrient composition of hazelnut (Corylus avellana L.) varieties cultivated in Turkey. Food Chem. 2006; 99(3):509-15. doi:10.1016/j.foodchem.2005.0 8.013.

23. Takemoto E, Okada IA, Garbelotti ML, Tavares M, Aued-Pimentel S. Composição química da semente e do óleo de baru (Dipteryx alata Vog.) nativo do município de Pirenópolis, Estado de Goiás. Rev Inst Adolfo Lutz. 2001; 60(2):113-7.

24. Fernandes DC, Freitas JB, Czeder LP, Naves MMV. Nutritional composition and protein value of the baru (Dipteryx alata Vog.) almond from the Brazilian Savanna. J Sci Food Agric. 2010; 90 (10):1650-5. doi: 10.10 02/jsfa.3997.

25. Küçüköner E, Yurt B. Some chemical characteristics of Pistacia vera varieties produced in Turkey. Eur Food Res Technol. 2003; 217(4):308-10. doi: 10.10 07/s00217-003-0763-7.

26. Matthäus B, Özcan MM. Quantitation of fatty acids, sterols, and tocopherols in turpentine (Pistacia terebinthus Chia) growing wild in Turkey. J Agric Food Chem. 2006; 54(20):7667-71. doi: 10.1021/ jf060990t.
27. Merrill AL, Watt BK. Energy value of foods: basis and derivation. Washington (DC): United States Departament of Agriculture; 1973. Agriculture Handbook, n.74.

28. Food and Agriculture Organization of the United Nations. Amino-acid content of foods and biological data on proteins. Rome: FAO; 1970. FAO Nutricional Studies, n.24.

29. Toledo A, Burlingame B. Biodiversity and nutrition: a common bath toward global food security and sustainable development. J Food Compos Anal. 2006; 19(6-7):477-83. doi:10.1016/j.jfca.2006.0 5.001.

30. Borges O, Gonçalves B, Carvalho JLS, Correia P, Silva AP. Nutritional quality of chestnut (Castanea sativa Mill.) cultivars from Portugal. Food Chem. 2008; 106(3):976-84. doi: 10.1016/j.foodchem. 2007.07.011.

31. Institute of Medicine. Dietary references intakes for energy, carbohydrate, fiber, fat, fatty acids, cholesterol, protein, and amino acids. Washington (DC): USA National Academies; 2005. p.589-768.

32. Motta Neto R, Guimarães SB, Silva SL, Cruz JN, Dias T, Vasconcelos PRL. Glutamine or whey-protein supplementation on alloxan-induced diabetic rats. Effects on CD4+ and CD8+ lymphocytes. Acta Cir Bras. 2007; 22(3):215-9. doi: 10.1590/S0102-865 02007000300010.

33. Ribeiro SR, Pinto Júnior PE, Miranda AC, Bromberg SH, Lopasso FP, Irya k. Weight loss and morphometric study of intestinal mucosa in rats after massive intestinal resection. Influence of a glutamine-enriched diet. Rev Hosp Clin. 2004; 59(6):349-56. doi: 10.1590/S0041-8781200400 0600007.

34. Griffiths RD, Jones C, Palmer, TEA. Six-month outcome of critically III patients given glutaminesupplemented parenteral nutrition. Nutrition. 1997; 13(4):295-302. doi: 10.1016/\$0899-900 7(97)00017-8.

35. Ros E, Núñez I, Pérez-Heras A, Serra M, Gilabert R, Casals $E$, et al. A walnut diet improves endothelial function in hypercholesterolemic subjects: a randomized crossover trial. Circulation. 2004; 109(13):1609-14. doi: 10.1161/01.CIR.000012 4477.91474.FF.

36. Alper CM, Mattes RD. Peanut consumption improves indices of cardiovascular disease risk in healthy adults. J Am Coll Nutr. 2003; 22(2):133-41.

37. Strunz CC, Oliveira TV, Vinagre JCM, Lima A, Cozzolino S, Maranhão RC. Brazil nut ingestion increased plasma selenium but had minimal effects on lipids, apolipoproteins, and high-density lipoprotein function in human subjects. Nutr Res. 
2008; 28(3):151-5. doi:10.1016/j.nutres.2008.0 1.004.

38. Organización Mundial de la Salud. Informe de una consulta mixta de expertos OMS/FAO. Dieta, Nutrición y Prevención de Enfermedades Crónicas. Genebra: OMS; 2003. OMS Serie de Informes Técnicos, n. 916.

39. Silva AGH, Cozzolino SMF. Cálcio. In: Cozzolino SMF. Biodisponibilidade de nutrientes. Barueri: Manole; 2007. p.456-81.

40. Henriques GS, Cozzolino SMF. Ferro. In: Cozzolino SMF. Biodisponibilidade de nutrientes. Barueri: Manole; 2007. p.508-32.

41. Yuyama LKO, Yonekura L, Aguiar JPL, Rodrigues MLCF, Cozzolino SMF. Zinco. In: Cozzolino SMF. Biodisponibilidade de nutrientes. Barueri: Manole; 2007. p.549-74.

42. Gonzaga IB, Martens A, Cozzolino SMF. Selênio. In: Cozzolino SMF. Biodisponibilidade de nutrientes. Barueri: Manole; 2007. p. 575-613.

43. Thomson CD, Chisholm A, McLachlan SK, Campbell JM. Brazil nuts: an effective way to improve selenium status. Am J Clin Nutr. 2008; 87(2):379-84.

44. Mann J. Cardiovascular diseases. In: Mann J, Truswell S, editors. Essentials of human nutrition. New York: Oxford University Press; 2002. p.298-334.

45. Jonnala RS, Dunford NT, Dashiiell KE. Tocopherol, phytosterol and phospholipid compositions of new high oleic peanut cultivars. J Food Compos Anal. 2006; 19(6-7):601-5. doi:10.1016/j.jfca.20 06.01 .005 .

46. Nissinen MJ, Gylling H, Miettinen TA. Effects of plant stanol esters supplied in a fat free milieu by pastilles on cholesterol metabolism in coloctomized human subjects. Nutr Metabol Cardiov Dis. 2006; 16(6):426-35. doi: 10.1016/j.numecd.2005.07.0 05.

47. Takeshita M, Katsuragi Y, Kusuhara M, Higashi K, Miyajima E, Mizuno K, et al. Phytosterols dissolved in diacylglycerol oil reinforce the cholesterollowering effect of low-dose pravastatin treatment. Nutr Metabol Cardiov Dis. 2008; 20(1):1-9. doi: 10.1016/j.numecd.2007.05.009.
48. Katan MB, Grundy SM, Jones P. Efficacy and safety of plant stanols and sterols in the management of blood cholesterol levels. Mayo Clin Proc. 2003; 78(8):965-78. doi: 10.4065/78.8.965.

49. Awad AB, Williams $H$, Fink CS. Effect of phytosterols on cholesterol metabolism and MAP kinase in MDA-MB 231 human breast cancer cells. J Nutr Biochem. 2003; 14(2):111-9. doi:10.1016/S0955-28 63(02)00274-7.

50. Bennani $H$, Drissi A, Giton F, Kheuang L, Fiet J, Adlouni A. Antiproliferative effect of polyphenols and sterols of virgin argan oil on human prostate cancer cell lines. Cancer Detec Prev. 2007; 31(1): 64-9. doi:10.1016/j.cdp.2006.09.006.

51. Amaral JS, Alves MR, Seabra RM, Oliveira BPP. Vitamin E compositions of walnuts (Juglans regia L.): a 3-year comparative study of different cultivars. J Agric Food Chem. 2005; 53(13):5467-72. doi: 10.10 21/jf050342u.

52. Cahoon EB, Hall SE, Ripp KG, Ganzke TS, Hitz WD, Coughlan SJ. Metabolic redesign of vitamin E biosynthesis in plants for tocotrienol production and increased antioxidant content. Nat Biotechnol. 2003; 21(9):1082-7. doi: 10.1038/nbt853.

53. Thomson C. Trace elements: selenium. In: Mann J, Truswell S, editors. Essentials of human nutrition. New York: Oxford University Press; 2002. p.172-81.

54. Samman S. Trace elements: zinc. In: Mann J, Truswell S, editors. Essentials of human nutrition. New York: Oxford University Press; 2002. p.159-64.

55. Brand-Miller J. Carbohydrates. In: Mann J, Truswell S, editors. Essentials of human nutrition. New York: Oxford University Press; 2002. p.11-29.

56. Jenab M, Ferrari P, Slimani N, Norat T, Casagrande C, Overad K, et al. Association of nut and seed intake with colorectal cancer risk in the European Prospective Investigation into Cancer and Nutrition. Cancer Epidemiol Biomark Prev. 2004; 13(10):15 95-603.

Recebido em: 12/5/2008

Aprovado em: 22/4/2009 